\title{
Integration of Building Maintenance Data in Application of Building Information Modeling (BIM)
}

\author{
Dooyong Ahn, Heesung Cha* \\ Department of Architectural Engineering, Ajou University, Suwon, South Korea \\ Email: ${ }^{\text {hsscha@ajou.ac.kr }}$
}

Received 10 May 2014; revised 10 June 2014; accepted 20 June 2014

Copyright (C) 2014 by authors and Scientific Research Publishing Inc.

This work is licensed under the Creative Commons Attribution International License (CC BY).

http://creativecommons.org/licenses/by/4.0/

c) (i) Open Access

\section{Abstract}

A typical building project has a long life in the maintenance stage. Also, the cost at this stage is enormously huge compared to planning, design and construction phases. In the earlier stage, which is planning or design phase, however, many project participants put little emphasis on the maintenance information. As a result, important maintenance data is missing and erroneously feedback to the 3D/BIM model. This research provides a generic process model for maintenance information management for building facilities. The authors have identified that there exist mostfrequently used information areas: checking information, material information, equipment information, supplier information, and maintenance history information. Each information area should be embedded in the BIM model in order to effectively feedback to the operation and maintenance stage in the project. Thus, the study has proposed a novel data format structure which can effectively link the 3D/BIM object with the maintenance data. The demonstration project shows how the data format structure is used. The contribution of this study is to provide guidance to a project practitioner by step-by-step approach in dealing with the significant maintenance information in the earlier stage of the construction project.

\section{Keywords}

3D/BIM, Building Information, Data Format, Facility Maintenance, Work Process

\section{Introduction}

A building has a typical life-cycle, i.e., planning, design, construction, operation and maintenance stages. During *Corresponding author.

How to cite this paper: Ahn, D. and Cha, H. (2014) Integration of Building Maintenance Data in Application of Building Information Modeling (BIM). Journal of Building Construction and Planning Research, 2, 166-172. 
this period, the performance of facilities is changed and quality and performance are degraded as structural members, parts and equipment etc. are aging. This reduces the user's convenience and safety and if the buildings are not appropriately managed, enormous cost is required [1]. So, the need to maintain the original features can be said to be great in terms of economic efficiency. However, as buildings get larger and complicated due to the modernization of construction technology, the current facility maintenance tasks and related information management reveal limitations in the conventional facilities maintenance process.

As the demand level for performance increasingly sophisticated due to the development of building technologies, equipment and finishing materials with various functions have been added to structures. It is said that this increases data to be managed extensively so the traditional method causes loss and decentralization of information [2] [3]. When the use of BIM becomes mandatory in the near future, this problem cannot be solved until integrating information into management process in the planning stage of the project and managing them systematically. Also, due to the problems resulting from the modernization of technologies and massive amount of data, more specific and systematic management are being sought from professional maintenance companies rather than in-house control by building owners themselves.

The purpose of this study is to integrate and generate data format required from design phase to construction and maintenance phases to use them in the entire life cycle of the building and aims at more efficient and systematic maintenance process. The result of this study facilitates the data usage especially in the maintenance stage which is currently at issue and improves the problems caused in the current maintenance work process by storing, updating and managing maintenance data in a more effective way.

\section{Research Methodology}

In the beginning, this study has conducted a rigorous literature review and re-visited research objectives. Once completing the previous research on the subject and examining the related topic, the authors investigated the concepts through theoretical considerations and explained study contents and analyzed the benefits and limitations of the study. First, in the problem analysis, we analyzed the actual conditions and problems of current maintenance work process through on-site survey and interviews with experts of the building maintenance team and re-conducted previous research search in order to combine the conventional maintenance work and the BIM-based management benefits. In a theoretical analysis, we found out the basic concept on BIM and examined the required functions in a BIM software, Revit. Based on this, we tried to improve the maintenance process by setting the research direction.

As research findings, we analyzed maintenance work process to classify it into each purpose and defined "data format" criteria by selecting information deemed necessary for maintenance work after identifying individual sub-work processes. The proposed BIM-based work process model has been successfully applied in a real case project and the potential benefits of this study have been discussed in the conclusion section.

\section{Theoretical Considerations}

\subsection{Definitions of BIM}

BIM stands for Building Information Modeling and can be said to be the technology of producing and managing all information applied in various fields during the entire life cycle of the project from the initial concept design to maintenance stage. BIM expresses each attribute information (features, structures, uses, etc.) of intelligent building objects (walls, slabs, windows, doors, stairs) by applying the parametric technology and immediately reflects change elements of the building by recognizing the relationship between each other [4]. Therefore, since characteristics, relationships, and information in all building objects can be obtained by the simulation using model data, BIM not only provides information on quantities, costs, schedule and list of materials to help rapid decision-making in the progress of projects of the construction industry but enables data analysis considering structure and environment.

BIM can be said to be an innovative technology and process being transformed in design, engineering, construction and maintenance of buildings. Recently, enormous information can be obtained about theories on fields that can be performed by BIM, many available BIM tools and problems faced. BIM can be said to be a proven technology but there is a difference in understanding of BIM concept between working group and management about what to do with BIM. However, BIM is constantly developing. There are some inefficient elements which 
are currently being improved but BIM is not in its initial stage any longer because AEC/O industry around the world started to put out results. By ultimately building and using information of facilities throughout the life cycle of building as a unified system through BIM, we try to introduce BIM and apply it to maximize the production efficiency and usability of information.

It is noteworthy that out of various BIM Software, Revit Architecture (hereinafter Revit) of AutoDeskhas been used in this study. Modeling level followed LOD (Level Of Detail) 5 by referring to BIM Application Guide of Vicosoft [5].

\subsection{UNIT SPEC}

Each member or every object has its own unique information. For example, a HVAC system in a facility has information such as production year of product, price, check cycle, specifications etc. that is, UNIT SPEC and building these in BIM space facilitates integrated management without separate documents during maintenance. Each UNIT or sector such as work information or materials information, company or history information may require different SPEC. In order to reduce unnecessary workload between modeling and prevent confusion, lists required during maintenance need to be organized and information suitable for each UNIT needs to be entered.

\subsection{Parameters}

Parameters are added to enter UNIT SPEC after modeling. Parameter can be added in "Project Parameter" of "Manage" tab in the BIM software and ID data value that can be modified with characters can be set. After adding the required items, checking is possible after selecting an object in the characteristic window of the main interface and input and modification are possible. After entering, information entered can be separately converted into listing. A table is created by selecting desired parameters or information that one wants to show in "Create a table" (See Figure 1).

In Figure 1, the list is only "Flooring” information out of various types of data entered after modeling. Parameters selected in "Create a table" are family (each member is called as "a family" in Revit), type, level. As shown, the information entered can be identified at a glance and input and modification are possible within the table. Also, revised information is mutually updated because the modeled object and table are interlocked.

Information organized through "Create a table" can be checked/entered/modified only in the program called Revit. This can be extracted with Microsoft Excel through "Export table" function and currently, most of the office work is made with Excel and it is easy to use it as the source of Internet web browser.

Floor Material List

\begin{tabular}{|c|c|c|}
\hline Family & Type & Floor Level \\
\hline Floor & S-S1 (TH150) & $1 \mathrm{~F}$ \\
\hline Floor & $\mathrm{S}-\mathrm{S} 1(\mathrm{TH} 300)$ & $1 \mathrm{~F}$ \\
\hline Floor & A-THK40 Light Weight Vapor Concrete & $1 \mathrm{~F}$ \\
\hline Floor & A-THK30 Floor Impact Sound Reducer & $1 \mathrm{~F}$ \\
\hline Floor & A-THK50 Cement Mortar & $1 \mathrm{~F}$ \\
\hline Floor & A-THK28 Cement Mortar & $1 \mathrm{~F}$ \\
\hline Floor & A-THK90 Light Weight Vapor Concrete & $1 \mathrm{~F}$ \\
\hline Floor & A-THK90 Light Weight Vapor Concrete & $1 \mathrm{~F}$ \\
\hline Floor & A-THK40 Cement Mortar & $1 \mathrm{~F}$ \\
\hline Floor & A-THK40 Light Weight Vapor Concrete & $1 \mathrm{~F}$ \\
\hline Floor & A-THK40 Cement Mortar & $1 \mathrm{~F}$ \\
\hline Floor & A-Reinforced Wood Flooring & $1 \mathrm{~F}$ \\
\hline Floor & A-THK50 Cement Mortar & $1 \mathrm{~F}$ \\
\hline Floor & A-THK10 Porcelain Tile & $1 \mathrm{~F}$ \\
\hline Floor & A-THK10 Porcelain Tile & $1 \mathrm{~F}$ \\
\hline Floor & A-THK40 Cement Mortar & $1 \mathrm{~F}$ \\
\hline Floor & A-THK10 Porcelain Tile & $1 \mathrm{~F}$ \\
\hline Floor & A-Natural Marble Floor Joist & $1 \mathrm{~F}$ \\
\hline Floor & A-Natural Marble Floor Joist & $1 \mathrm{~F}$ \\
\hline Floor & A-Bathroom Door Threshold & $1 \mathrm{~F}$ \\
\hline Floor & A-THK17 Terrazzo Tile & $1 \mathrm{~F}$ \\
\hline Floor & A-THK10 Porcelain Tile & $1 \mathrm{~F}$ \\
\hline Floor & A-THK10 Porcelain Tile & $1 \mathrm{~F}$ \\
\hline Floor & A-THK10 Porcelain Tile & $1 \mathrm{~F}$ \\
\hline Floor & A-THK10 Porcelain Tile & $1 \mathrm{~F}$ \\
\hline Floor & A-Frostproof Insulation & $1 \mathrm{~F}$ \\
\hline Floor & A-THK10 Polishing Tile & $1 \mathrm{~F}$ \\
\hline Floor & A-THK20 Polishing Tile & $1 \mathrm{~F}$ \\
\hline
\end{tabular}

Figure 1. List of flooring material. 


\section{BIM-Based Facility Management Work Flow}

The key principle how the required information is configured in the current maintenance process can be checked in the previous section. The data used in the current maintenance leads to the extraction of necessary information by gathering information of the initial building. At this time, most of 3D Model built by using BIM Tool at design-construction stage is missing from necessary information. Also, information extracted like this is managed without being integrated into CAD information, document information, Excel Information etc. Due to the absence of such an integrated management system, missing and loss of data occur so effective maintenance is not achieved. Due to this problem, hands-on workers also recognize the need for an integrated information management program of maintenance data. However, when building initial data to use an integrated management program, missing and loss of necessary information occurred already due to unsystematic management and it is difficult to integrate data and therefore, the current work is not improved. To solve this problem, we try to take advantage of maintenance data without missing and loss of data by using BIM Tool and comprehensively managing when building initial data.

The entire life cycle of a building is used without missing data by using a function such as the aforementioned UNIT SPEC and/or parameters among the functions of BIM Tools and entering information required for maintenance in 3D/BIM Model which are widely used in crash detection check, estimation, and scheduling analysis during design and construction stages. Data built like this can be easily extracted via Microsoft Excel so the utilization of Data base of web browser is excellent and conversion for other FM (Facility Management) program is also easily possible. By taking into account the limitations of the exclusive tendency for work change of hands-on workers of current maintenance and lack of BIM Tool hands-on workers and extracting data organized by Excel rather than using BIM Tool itself, this study is conducted in the direction of comprehensively managing only data required for maintenance without changes in the flow of current work as seen in Figure 2.

Throughout the literature review and preliminary survey of practitioners, five key information items on maintenance were classified and derived. It was classified into inspection job information, material Information, equipment information, contractor information, and maintenance history information. Maintenance tasks were analyzed based on five key functions derived like this. Maintenance tasks derived through this analysis can be classified as Table 1.

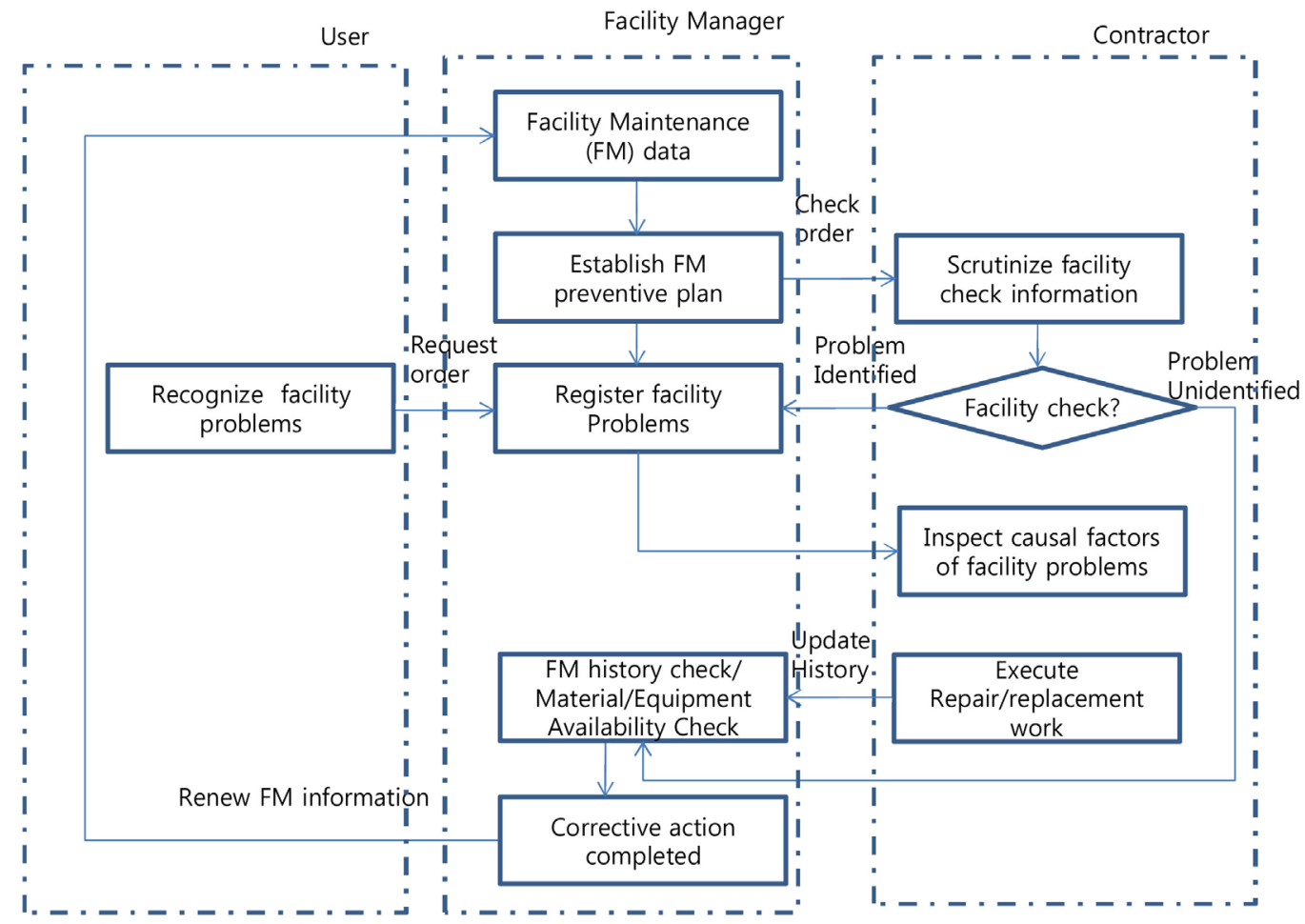

Figure 2. ProposedBIM-based facility maintenance work process. 
Table 1. Facility Maintenance (FM) work breakdown structure.

\begin{tabular}{|c|c|c|c|}
\hline FM Work & Description & Main Information & Information User \\
\hline $\begin{array}{l}\text { Inspection job } \\
\text { information }\end{array}$ & $\begin{array}{c}\text { Managing preventive repair } \\
\text { information, material, repair } \\
\text { time, repair guideline, subcontract information }\end{array}$ & $\begin{array}{l}\text {-Maintenance check cycle } \\
\text {-Maintenance check plan schedule } \\
\text {-Maintenance check manual }\end{array}$ & $\begin{array}{l}\text {-Maintenance company } \\
\text {-Laborer/subcontractor }\end{array}$ \\
\hline $\begin{array}{l}\text { Material } \\
\text { information }\end{array}$ & $\begin{array}{l}\text { Managing material information, } \\
\text { re-procurement/inventory, history, } \\
\text { supplier/manufacturer information }\end{array}$ & $\begin{array}{l}\text {-Check/replacement cycle } \\
\text {-Cost information } \\
\text {-Inventory information }\end{array}$ & $\begin{array}{l}\text {-Maintenance company } \\
\text {-Laborer/subcontractor }\end{array}$ \\
\hline Equipment & $\begin{array}{l}\text { Managing equipment-related information, } \\
\text { check/replacement history, cost, time, } \\
\text { supplier/manufacturer information }\end{array}$ & $\begin{array}{l}\text {-Check/replacement cycle } \\
\text {-Cost information } \\
\text {-Equipment-related information }\end{array}$ & $\begin{array}{l}\text {-Maintenance company } \\
\text {-Laborer/subcontractor }\end{array}$ \\
\hline Contractor & $\begin{array}{l}\text { Managing service providers, material } \\
\text { supplier information, material information }\end{array}$ & $\begin{array}{l}\text {-Equipment location information } \\
\text {-Drawings } \\
\text {-Estimation }\end{array}$ & $\begin{array}{l}\text {-Maintenance company } \\
\text {-Laborer/subcontractor } \\
\text {-User }\end{array}$ \\
\hline $\begin{array}{l}\text { Maintenance } \\
\text { history }\end{array}$ & $\begin{array}{l}\text { Managing building status } \\
\text { and repair history }\end{array}$ & $\begin{array}{c}\text {-FM manual } \\
\text {-Check status } \\
\text {-Experience information }\end{array}$ & $\begin{array}{l}\text {-Maintenance company } \\
\text {-Laborer/subcontractor } \\
\text {-User }\end{array}$ \\
\hline
\end{tabular}

Data Format was presented by identifying maintenance information required in each process from the initial information which is available by management based on maintenance tasks system classified in the aforementioned process.

First, in case of inspection work, the work process is to establish the maintenance plan and then direct preventive inspection and regular maintenance work and adjust inspection criteria by analyzing work history after working. Information required such inspection work information management is preventive maintenance history when establishing maintenance plan, number of execution, expected personnel, date of work, required materials, company name, working time, costs etc.

Second, the process of material information management is to plan work first and then check material information and request a purchase order when necessary. Once the inventory is checked, the work is conducted and material information is planned after completion of the work. At this time, first, material name and material location are required when planning the work and after checking the current quantity by checking material information, information of suppliers, manufacturers, material unit cost, re-order quantity are needed for the purchase request when necessary. Finally, a change quantity history is needed in the information update process after completing the maintenance work. Third, the equipment related work process should be initiated by checking the equipment Information and then the requested work is carried out. After completing the work, the equipment Information should be updated through a maintenance data update process. At this time, various types of information including an equipment type, a manufacturer, a supplier, a managing director, an installation date and purchase price, are needed when identifying equipment Information and if spare parts are required when repairing, the name and quantity of the spare parts are required. Also, when updating maintenance data after completing work, changes in maintenance history are required.

Fourth, contractor (company) information is mainly classified into the information of a materials supply company required when purchasing materials and the information of a supply service company required when contracting services and planning maintenance. At this time, information such as company name and company type, company telephone number, person in charge, supply service, supply materials, supply amount are needed. Finally, in a long-term period of FM information management, completion date of a building, building drawings and building maintenance history should be well preserved.

Likewise, maintenance criteria using BIM are presented by checking the original information by maintenance work system, selecting essential information based on the process of actual maintenance work and defining it as maintenance "Data Format" and adding it as a parameter when constructing a BIM-based 3D model. Also, the utilization and potential benefits are predicted by entering information of actual Data Format in 3D modeling for a particular project.

\section{Case Study}

A 3D Modeling was carried out by selecting a unit household for a residential building in Jeonju-Wanju Innovation City A-14BL in South Korea. As shown in Figure 3, the modeling was constructed for architecture, struc- 
ture, Mechancial/Electrical/Plumbing, and interior.

Figure 3 also shows a screenshot to enter UNIT SPEC in the modeled building. Since the operation is done in three-dimensional space, it is easy to check the position and shape of the object in association with its value of the assigned "character type", which can be registered with only one simple typing.

Figure 4 is an example and the format of arranging materials management information of lighting fixtures into a table and then extracting it with a Microsoft Excel. Although it is not proficient in BIM modeling, this case study indicates that a data extraction is possible by using the initial built-in BIM model information in an Excel-oriented practice.

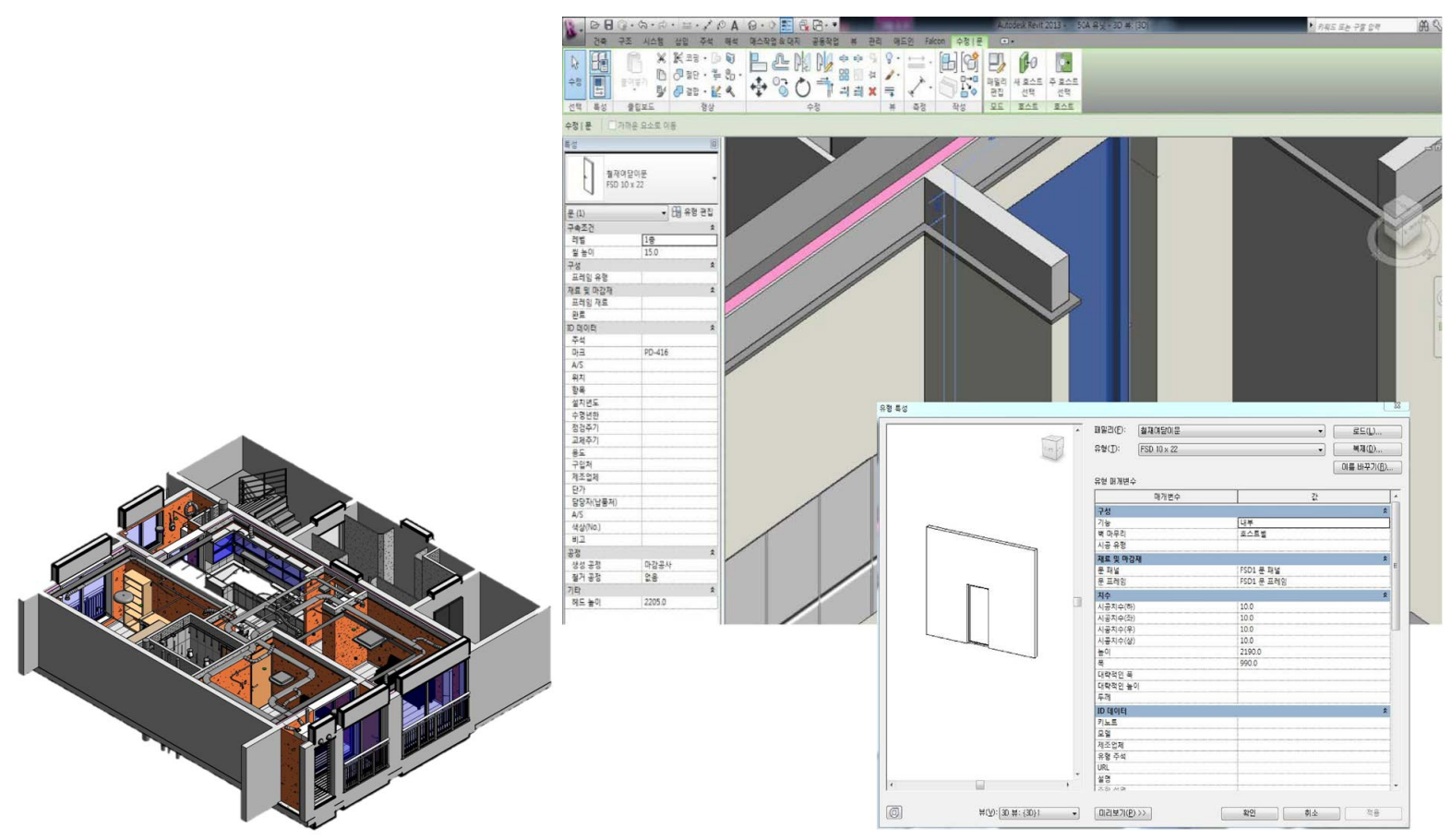

Figure 3. 3D/BIM model of case project.

\begin{tabular}{|c|c|c|c|c|c|c|c|c|c|}
\hline \multirow{24}{*}{$\begin{array}{l}\text { Electrial } \\
\text { Equipment }\end{array}$} & Type & Name & Location & $\begin{array}{c}\text { Unit } \\
\text { Price }\end{array}$ & $\begin{array}{l}\text { Current } \\
\text { Inventoy }\end{array}$ & $\begin{array}{c}\text { Re-order } \\
\text { Amount }\end{array}$ & $\begin{array}{c}\text { Changed } \\
\text { Amount }\end{array}$ & Supplier & Manufacturer \\
\hline & \begin{tabular}{|l}
50 TYPE Emergency Light \\
\end{tabular} & EL $11 W \times$ & $1 \mathrm{~F}$ & 10,00 & 5 & 0 & & South ENG & South ENG \\
\hline & EL $11 \mathrm{~W} \times 1: 1$ & & & & & & & & \\
\hline & 50 TYPE Dinning Light & EL 20W $\mathrm{x} 1$ & $1 \mathrm{~F}$ & 7,000 & 3 & 2 & 2 & South ENG & South ENG \\
\hline & EL 20W x1:1 & & & & & & & & \\
\hline & 50 TYPE Balcony Light & EL 20W $\times 1$ & $1 \mathrm{~F}$ & 3,000 & 3 & 0 & 0 & South ENG & South ENG \\
\hline & EL 20W $\times 1: 2$ & & & & & & & & \\
\hline & 50 TYPE Corridor Light & EL 20W $\times 1$ & $1 \mathrm{~F}$ & 5,000 & 3 & 0 & $\underline{0}$ & South ENG & South ENG \\
\hline & EL 20W $\times 1: 2$ & & & & & & & & \\
\hline & 50 TYPE Bathroom Light & EL 20W x1 & $1 \mathrm{~F}$ & 2,000 & 3 & 2 & 2 & South ENG & South ENG \\
\hline & EL 20W $\times 1: 2$ & & & & & & & & \\
\hline & 50 TYPE Corridor Light & EL 20W $\times 2$ & $1 \mathrm{~F}$ & 2,500 & 5 & 0 & $\underline{0}$ & ST\&V & ST\&V \\
\hline & EL $20 \mathrm{~W} \times 2: 1$ & & & & & & & & \\
\hline & 50 TYPE Bedroom Light & FPL $32 \mathrm{~W} 2$ & $1 \mathrm{~F}$ & 3,000 & 5 & 0 & 0 & ST\&V & ST\&V \\
\hline & \begin{tabular}{|ll} 
FPL $32 W \quad 2: 1$ \\
\end{tabular} & & & & & & & & \\
\hline & 50 TYPE Kitchen Light & FPL 32W 2 & $1 \mathrm{~F}$ & 2,500 & 2 & 1 & 1 & ST\&V & ST\&V \\
\hline & \begin{tabular}{|lll} 
FPL $32 W \quad 2: 1$ \\
\end{tabular} & & & & & & & & \\
\hline & 50 TYPE Master Bedroom L & FPL $32 \mathrm{~W} 3$ & $1 \mathrm{~F}$ & 3,000 & 5 & 0 & $\underline{0}$ & ST\&V & ST\&V \\
\hline & FPL 32W $3: 1$ & & & & & & & & \\
\hline & 50 TYPE Living Room Ligh & FPL $55 \mathrm{~W} 3$ & $1 \mathrm{~F}$ & 4,000 & 5 & 0 & $\underline{0}$ & ST\&V & ST\&V \\
\hline & FPL 55W $3: 1$ & & & & & & & & \\
\hline & 50 TYPE Artwal1 Embedded & HAL $50 \mathrm{~W} x$ & $1 \mathrm{~F}$ & 6,000 & 3 & 0 & $\underline{0}$ & ST\&V & ST\&V \\
\hline & HAL $50 \mathrm{~W} \times 1: 2$ & & & & & & & & \\
\hline & Sum: 15 & & & & & & & & \\
\hline
\end{tabular}

Figure 4. Automated extraction of list of facility maintenance. 


\section{Conclusions}

The purpose of this study is to save time and money by conducting BIM-based FM tasks which are identified in a traditional FM work process more efficiently and systematically. If the facility maintenance work is carried out with the proposed BIM model-based process, the building maintenance work process will be robust and more efficient work will be conducted by each sub-process stage.

The main advantage of the proposed process model is an "easy-to-manage" data format. For example, when there is a need to conduct the maintenance process which may use the maintenance data input for a preventive inspection planning, an approximate budget can be provided by simply multiplying the expected inflation factor of this year compared to the previous years. In addition, it is not trivial to obtain the corresponding data because the maintenance work of the previous year and that of this year are bound to be different. If maintenance work is performed with a BIM model, errors will be significantly reduced by appropriating practical budget through the embedded information integrated with Microsoft Excel file and it is easy to manage the maintenance budget because a clearer preventive maintenance plan can be established. Furthermore, when there is an instructing inspection in the preventive inspection planning, "information missing" occurs due to the complicated MS Excel files and handwritten documents. When defects occur in equipment maintenance because of errors in preventive inspection, unplanned costs are incurred in the existing work. On the other hand, if the maintenance work is performed with BIM, work efficiency will be improved due to the correct information checking of equipment and defects as well as additional costs will also be reduced because of the reduced "check missing".

In a conventional method, the updating process for maintenance data requires a large amount of time and cost due to inconsistency in data management, which mainly focused on human-oriented handwritten documents. But efficiency improvement and cost reduction of maintenance work are expected by integrating information management using BIM applications.

Currently, BIM is attracting a huge attention as many public-sectors publicly announce mandatory application of BIM-based design and it is playing a crucial role in the construction industry. However, BIM-based construction has not been activated fully; instead, they are being partially used in design and/or construction stage. Furthermore, in the field of construction work, the hands-on workers have an exclusive tendency for a new way of working so there are a lot of difficulties in applying new way of working process. Thus, this study uses BIM Data Format in maintenance work by converting the relevant data into Excel-based worksheet. Although there is still a limit in using BIM program alone in the entire life cycle of a building, this study will be helpful in enhancing the BIM application in the maintenance stage by integrating the BIM model with the maintenance data in an effective way.

\section{Acknowledgements}

This research was supported by Ajou University (grant number: S-2013-G0001-00169) and Basic Science Research Program through the National Research Foundation of Korea (NRF) funded by the Ministry of Education (grant number: 2012R1A1B3001009).

\section{References}

[1] Kirk, S. and Dell'isola, A. (1995) Life Cycle Costing for Design Professionals. McGraw-Hill, NY.

[2] Becerik-Gerber, B., Jazizadeh, F., Li, N. and Calis, G. (2012) Application Areas and Data Requirements for BIM-Enabled Facilities Management. Journal of Construction Engineering and Management (ASCE), 138, 431-442. http://dx.doi.org/10.1061/(ASCE)CO.1943-7862.0000433

[3] Goedert, J. and Meadati, P. (2008) Integrating Construction Process Documentation into Building Information Modeling. Journal of Construction Engineering and Management (ASCE), 134, 509-516. http://dx.doi.org/10.1061/(ASCE)0733-9364(2008)134:7(509)

[4] Eastman, C., Teicholz, P., Sacks, R. and Liston, K. (2008) BIM Handbook: A Guide to Building Information Modeling for Owners, Managers, Designers, Engineers, and Contractors. 2nd Edition, Wiley, NJ. http://dx.doi.org/10.1002/9780470261309

[5] Leite, F., Alcamete, A., Akinci, B., Atasoy, G. and Kiziltas, S. (2011) Analysis of Modeling Effort and Impact of Different Levels of Detail in Building Information Models. Automation in Construction, 20, 601-609. http://dx.doi.org/10.1016/j.autcon.2010.11.027 
Scientific Research Publishing (SCIRP) is one of the largest Open Access journal publishers. It is currently publishing more than 200 open access, online, peer-reviewed journals covering a wide range of academic disciplines. SCIRP serves the worldwide academic communities and contributes to the progress and application of science with its publication.

Other selected journals from SCIRP are listed as below. Submit your manuscript to us via either submit@scirp.org or Online Submission Portal.
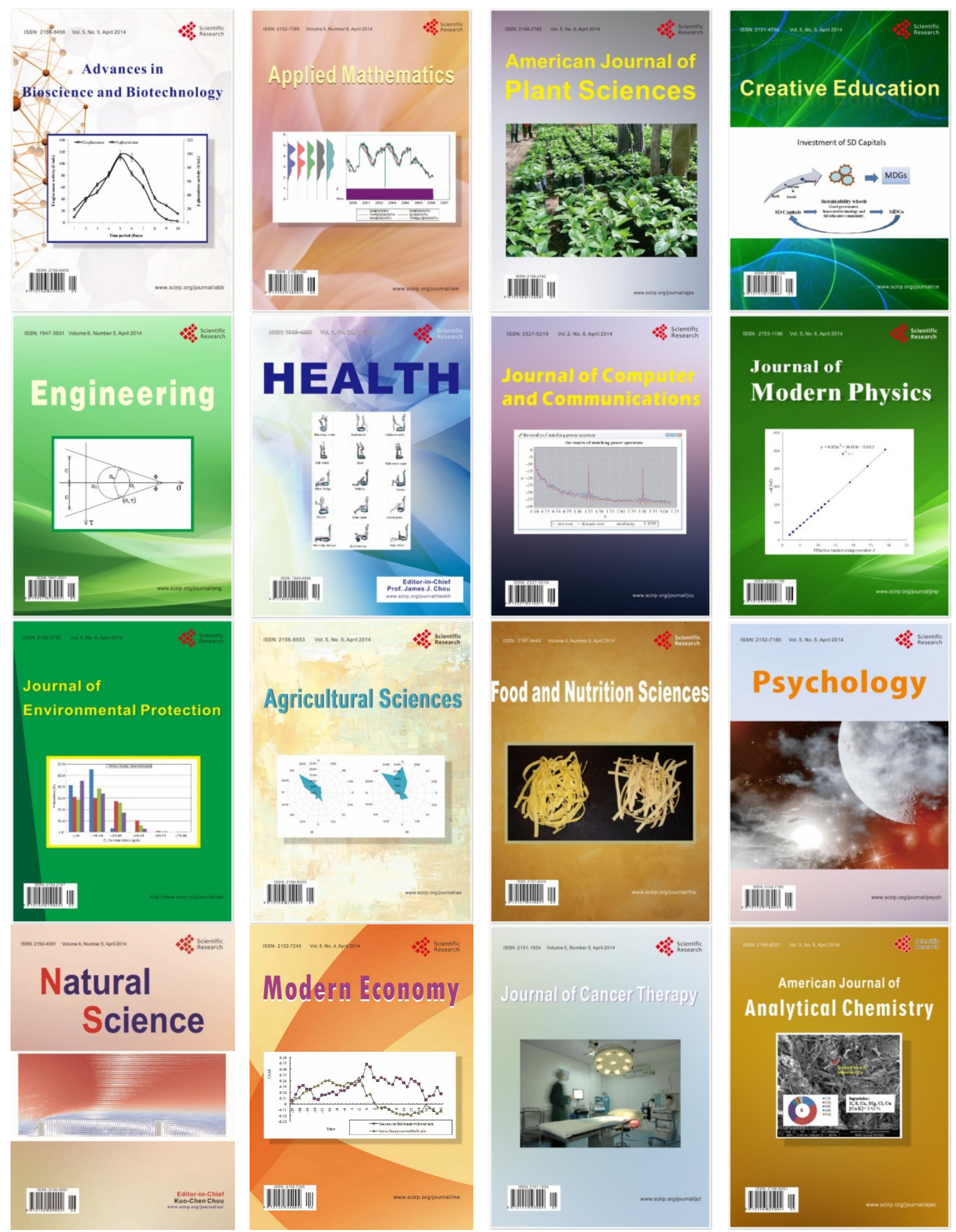